\title{
Reflexivity in Organization and Management Theory: A Study of the Production of the Research "Subject"
}

\author{
Cynthia Hardy \\ Department of Management \\ University of Melbourne \\ Parkville 3052 \\ Australia \\ Fax: 61-3-9349-4292
}

Email: C.Hardy@ecomfac.unimelb.edu.au

\author{
Nelson Phillips \\ Faculty of Management \\ McGill University \\ 1001 Sherbrooke West \\ Montreal, Canada H3A 1G5 \\ Fax: 1-514-398-3876 \\ Email: Phillips@management.mcgill.ca \\ Stewart Clegg \\ School of Management \\ University of Technology, Sydney \\ PO Box 123 \\ Broadway, NSW 2560, Australia \\ Fax: 61-2-9514-3602; \\ Email: S.Clegg@uts.edu.au
}

The authors would like to acknowledge the financial support of: Social Sciences and Humanities Research Council of Canada, Les Fonds pour la Formation des Chercheurs et l’Aide à la Recherche du Quebec, McGill University and the University of Melbourne. 


\section{Reflexivity in Organization and Management Theory: \\ A Study of the Production of the Research "Subject"}

\section{Abstract}

In this paper, we draw on actor-network theory to reflexively investigate the role of the researcher and the research community in the production of a research subject. We review our earlier work, which explores how the dynamics of refugee systems help to produce the research subject — in this case, the refugee. We then use ideas from actor network theory (ANT) to move beyond the more conventional institutional and discursive analyses that are used in these articles. We include not just the activities of actors in the refugee system in our analysis, but also our own activities as researchers, as well as those of the broader research community. We use the concept of translation to explore the role of these actors in the processes of social construction that produce refugees as a subject of academic study, which is related to, but distinct from, the "social" subject produced in the social setting under study. Generalizing from our own research experience, we argue for a reconceptualization of reflexivity in organization and management theory, which moves beyond the common view of heroic individuals struggling to understand and manage their role in their research towards an understanding of reflexivity as involving the research community as a whole.

KEY WORDS: reflexivity, actor-network-theory, organization and management theory, research methods 


\section{Introduction}

In this paper, we reflexively explore the role of the researcher and research community in the production of research subjects. Using our own work on refugees as a research site, we explore how the "refugee" as a research subject is produced through a complex process of social construction involving ourselves, the various groups within the refugee determination system, and the wider research community. In reflexively studying the production of our own research, we draw on actor network theory (ANT) to present the engagements between a network of actors, which includes ourselves, interviewees, as well as specific members of the research community such as individual editors, reviewers and journals. In this way, we extend work on reflexivity in organization and management theory (OMT) to provide a framework allowing us to incorporate the research site, the researcher and the research community in our analysis.

Work on reflexivity and the social production of scientific "facts" is well developed in areas like the sociology of science and social science methodology (e.g., Clifford and Marcus, 1986; Latour, 1987; Woolgar, 1988; Ashmore, 1989; Bourdieu and Wacquant, 1992; Mulkay, 1992; Marcus, 1994; Denzin and Lincoln, 1994). These issues have, however, attracted far less attention in OMT, although this interest is increasing (e.g., Willmott, 1993; Linstead, 1994; Chia, 1996; Hatch, 1996; Alvesson, 1999; Holland, 1999). Some work has reflected on the nature of theorizing and the status of truth in the field of organization studies (e.g., Astley, 1984; Sandelands and Drazin, 1989; Mauws and Phillips, 1995; Kaghan and Phillips, 1998). Other work has deconstructed classic texts to show their hidden assumptions and strategic use of language (e.g., Kilduff, 1993; Calás and Smircich, 1991). The development and progression of particular areas of research such as strategy (Knights and Morgan, 1991) and culture (Smircich and Calás, 1987) have also been the subject of reflexive 
interrogation. Another interest has been the use of rhetorical devices by researchers in carrying out research and how this affects the results of research (e.g., Linstead, 1994) and the likelihood of publication (e.g., Watson, 1995).

While these approaches to reflexivity vary, most aim at conducting research in a way that turns back upon, and takes account of, itself (e.g., Hardy and Clegg, 1997; Chia, 1996; Holland, 1999). Reflexive research in the organizational literature has emphasized the inclusion of the researcher in the subject matter he or she is trying to understand. Consequently, studies have paid particular attention to the relationship between the researcher and the research subject (e.g., Jeffcutt, 1994; Hatch, 1996; Easterby-Smith and Malina, 1999) and, particularly, the limitations of researchers in representing the subjects under study and their effect on the creation of "knowledge". Drawing on ANT, however, we show that, to conduct reflexive research in organization and management theory, we cannot confine our attention to the relationship between researchers and the research subject, but must also examine the relationship between researchers and the research network of which they are a part.

Our interest, therefore, is in extending approaches to reflexivity in OMT that focus on the role of the researcher. Our analysis makes a number of contributions. First, using ANT, we present an empirical study of the production of organizational research to explore the role of several actors in the production of knowledge and to understand how the resulting research subject was shaped by these dynamics. Second, this approach enables us to differentiate between the refugee as a subject in the refugee system and the refugee as a subject of research. The former emerges at the intersection of struggles between actors in the refugee system. The latter is produced by a broader network that includes the strategies of researchers and the protocols of the research community. While this differentiation has been drawn before, ANT provides another way to understand, and even more importantly to explore, this 
difference. Third, by understanding the differences between social and research subjects, we are better placed to engage in reflexive research and to ascertain the effects of our research on our research sites. Understanding more clearly the way in which the researcher and research community shape the production of the research subject provides a basis for understanding how our constructions affect the social worlds that we study. Fourth, based on our exploration of our own work, we present an alternative definition of reflexivity that emphasizes the role of the research community in the research process and therefore points to the way in which reflexivity is largely a community level concern.

The paper is organized as follows. We first discuss the growing interest and concern with reflexivity in the organization and management literature. We then outline some ideas from ANT that we find useful in exploring the production of research. Third, we briefly describe the findings of our earlier work on refugees. We then adopt a "reflexive” approach to show how we, as researchers, and the research community are implicated in the production of research. Finally, we present and discuss some ramifications of our study for research in organization and management theory.

\section{Reflexivity}

Reflexivity involves reflecting on the way in which research is carried out and understanding how the process of doing research shapes its outcomes (Holland, 1999). It has appeared in the literature in a number of guises. According to Linstead (1994), a lack of reflexivity from a positivistic point of view has been generally equated with the existence of bias on the part of the researcher. Bias is assumed to distort the "true" picture and should, therefore, be eliminated.

Given the customary assumption that the scientific community has achieved knowledge which is closely and increasingly 'isomorphic to the structure of reality', it has been seen to follow necessarily that the members of that community have been predominantly open-minded, distinterested, impartial, 
independent, self-critical, and so on, in their intellectual endeavours (Mulkay, 1992: 63).

Within interpretative social science, similar pressures appeared during the 1950s, 1960s, and 1970s (Denzin and Lincoln, 1994). Consequently, the rigorous methods of researchers like Campbell and Stanley (1963), Becker (1970), and Glaser and Strauss (1967) were advocated as ways to produce valid, reliable and objective research accounts even in the case of qualitative work. The responsibility of researchers was to declare their biases and to make all attempts to remove them from their work using whatever techniques were available.

Over time, however, many social scientists came to the conclusion that the quest for objectivity in research was hopeless (Gouldner, 1970). They believed that the values of researchers could never be eradicated from their work and no amount of methodological technique or declarations of bias could strip them of their theoretical presuppositions (Linstead, 1994).

From the newer philosophical perspective there is no value in identifying a set of social norms which is designed to minimise distortion; partly because science is not conceived as an enterprise concerned with the definite representation, but also because it would be assumed that the meaning of normative principles would vary in accordance with changes in interpretive context (Mulkay, 1992:65-6).

Reflexivity thus became less concerned with removing biases than with rendering them visible though personal disclosure, so that readers could take them into account.

However, even this approach to reflexivity met with criticism. First, it was seen as a device to invite trust on the part of readers who had inadequate information or time to verify the research account. Second, it was argued that complete self-knowledge was unattainable — the idea that the researchers could increase the objectivity of their work by revealing aspects of themselves was undermined by the fact that such accounts are inherently highly subjective. Third, this approach still assumes that the researcher is passive and exhorts them to behave as though bias does not exist when, in fact, it does (see Linstead, 1994). As this 
questioning continued, key assumptions of researchers started to break down. For example, qualitative research had been based on the idea that:

qualified, competent observers can with objectivity, clarity, and precision report on their own observations of the social world, including the observations of others. Second, researchers have held to a belief in a real subject, or real individual, who is present in the world and able, in some form, to report on his or her experiences (Denzin and Lincoln, 1994: 11-12).

The growth of postmodern and poststructuralist work undermined both these premises — that subjects could exist in any "real” sense (e.g., Rorty, 1989; Gergen, 1991) and that researchers could objectively report on them. There were, then, no objective observations, only observations that were socially situated in the worlds of the observer and the observed (e.g., Denzin and Lincoln, 1994; Chia, 1996).

Writers in OMT became increasingly concerned about the question of authorial identity (e.g., Parker, 1992) and the tendency of researchers to speak for — and take over — their research subject (e.g., Jeffcutt, 1994). “Confessional melodramas” started to emerge in which the researcher presented the particularity of his or her experience and declared their authorial personality (Jeffcutt, 1994: 250). They did so not to reveal bias so that it might be discounted, nor to create trust concerning the author's reliability as a research instrument, but, instead, to present their experiences for interpretation by the reader (Linstead, 1994).

Researchers interrogate their own world as well as that of their subjects and generate new insights by investigating interruptions. Their research is neither self nor subject oriented but is concerned with the dialectics of the relationship (Linstead, 1994: 1327).

Reflexivity in these circumstances helped to open up research to multiple readings and to highlight that any research text was merely one representation among many possible representations (Jermier 1985). It also aimed at increasing the researcher's capacity to become involved in the experience under investigation and to allow the reader a voice in constructing meaning (Linstead, 1994). In contesting the de-humanization of social science 
associated with the scientific method, this form of reflexive research was increasingly drawn towards the humanities, as social scientists became more self-consciousness about their writing, pursuing reflexivity by using fiction, narrative, metaphor, and media (e.g., Richardson, 1994; O’Connor, 1995; Phillips, 1995; Hatch, 1996).

Critics have argued, however, that this approach to reflexivity has tended to draw attention away from the research subject and to refocus it on the researcher as subject (Clegg and Hardy, 1996). The interest in the researcher has also led to neglect concerning the research community of which the researcher is a part. The researcher is seen as a form of hero (Jeffcutt, 1994) — a free agent, who is largely disconnected from the professional networks of individuals and institutions in which they are embedded. Yet, as Jeffcutt (1994) acknowledges, the research "quest” is shaped by the need to submit doctoral theses, publish articles, appear at conferences, etc. The researcher is subjected to and resistant against the controls embedded in the research process, and neither the research subject nor the researcher can escape them (Hardy and Clegg, 1997).

This broader approach indicates that knowledge is not created by the actions of individual researchers but by multiple interactions within research communities. As studies in the sociology of science have shown, scientific facts are produced not only by the aggregated actions of different researchers, but also institutionalized practices, channels of dissemination, gatekeepers, universities, research councils, etc. As Latour (1987: 29) points out, the construction of facts is a collective process (e.g., Latour and Woolgar, 1979; KnorrCetina, 1981; Mulkay, 1992; Kaghan and Phillips, 1998).

Knowledge is not something that people possess in their heads, but rather, something that people do together (Gergen, 1991: 270).

Our interest, therefore, is not only in how researchers impact upon the research process and shape its outcomes, but also in the role played by the wider research community. 
In summary, we are interested in reflexivity in terms of understanding the role of the research process in producing the subjects of that research, as well as the ways in which processes and actors produce and stabilize the "facts" that constitute research. To be reflexive in this way, we must include an analysis of the researcher and of the research community.

\section{Actor Network Theory}

We draw on ANT (e.g., Callon and Latour 1981; Callon 1986; Latour 1987; Law, 1991; 1994; Law and Hassard, 1999) to develop a framework encompassing researchers, research community and research subjects alike. ANT is particularly useful in this case as it explicitly challenges conventional categories of actors and has been widely applied to social studies of science. From this perspective, any analysis must include a consideration of the networks of actors involved in the production of research: the actors in the domain under investigation; the researchers carrying out the study; and the broader research community in which the research is produced and disseminated.

While we draw on several ideas from ANT, our goal in this paper is not to contribute to the development of ANT but, rather, to contribute to the ongoing discussion of reflexivity in OMT. We therefore draw selectively from ANT, while retaining a stronger view of agency than often appears in the ANT literature and focusing primarily on human actors. ${ }^{1}$ We also adopt a different focus than is commonly adopted in the actor network research by studying ourselves and our role in the production of the research subject instead of stopping our analysis at the boundary of our own research analysis (Nowotny, 1990). For example, when studying the role of researchers in the domestication of scallops in St. Brieuc Bay, Callon (1986) ended his analysis without including himself and his research project in the analysis.

\footnotetext{
${ }^{1}$ While Law (1999) and Latour (1999) have reservations, other writers, such as Newton (1996), have used a similar approach to us in extending the discussion of agency and collapsing the social and natural worlds in ANT (also see Star, 1991; Lee and Brown, 1994).
} 
[T] he notion of 'constructed reality' which is frequently used as a means of legitimizing the authenticity of organizational accounts is rarely 'turned back' on the researchers/writers themselves. Their own accounts are presented as if they have been somehow been able to avoid socially constructing the claims they themselves make (Chia, 1996: 84).

In this paper, we therefore expand our earlier analyses of refugees - which hinge on the notion of a socially constructed reality — to include our own research activities (see Woolgar and Ashmore, 1988) viewed through the lens of ANT.

Actor-network theory hinges on the concept of translation where "a few obtain the right to express and to represent the many silent actors of the social and natural worlds they have mobilized”. Researchers following this approach examine "the way in which actors are defined, associated and simultaneously obliged to remain faithful to their alliances” (Callon 1986: 224). There are four stages of translation during which the identities and relationships of other actors are defined and consolidated in ways that commit them to actions that reinforce the central position of the translating actor. During problematization, actors seek to become indispensable by defining the "problems" of other actors and suggesting how they would be solved by passing through “obligatory passage points”. These obligatory passage points form a system of associations that define the identities and goals of participants in ways that reaffirm the centrality of the translating actors. Interessement comprises a series of processes by which actors lock all other actors into the roles proposed for them during problematization, thereby stabilizing identities and goals. Since identities emerge in a competitive arena, actors build barriers to keep out other identities. Enrolment comprises a set of strategies in which actors encourage participation, obtain consent, and address resistance through seduction, transaction, discussion etc. Mobilization refers to methods that ensure representatives of the various collectivities will, in fact, be followed by them.

These strategies help to create convergence by locking actors into the network. The more fixed or stable it appears, the more "real" and durable it becomes, and the less 
controversy and ambiguity are evident (Newton, 1996). The aim, then, is to put relations between actors into "black boxes" where they become a matter of indifference — scientific “facts”, technical artefacts, modes of thought, habits, forces, objects (Latour, 1987).

Before the elements dominated by the actor could escape in any direction, but now this is no longer possible. Instead of swarms of possibilities, we find lines of force, obligatory passing points, directions and deductions (Callon and Latour, 1981: 286-7).

We will use these ideas to explore our own research on refugees. Before doing so, we will briefly present this research in the next section.

\section{Research on Refugees}

In this case, our own research on refugees, including this paper, represents our research site. We therefore provide an overview of the findings of our earlier work on refugee systems and the production of refugees (e.g., Hardy 1994; Phillips and Hardy 1997; Hardy and Phillips 1998, 1999; Lawrence and Hardy 1999). We begin by outlining the methodology used in the study. We then describe the "official” story of how refugees are produced. Finally, we briefly recount the results of our research that challenge this official story to argue that refugee systems and refugees are the products of complex processes of social construction.

\section{Methodology}

Our work has examined refugee systems in three countries — Canada, the UK and Denmark. The 1948 United Nations (UN) Universal Declaration of Human Rights asserts that individuals have the right to seek asylum from persecution in other countries. The UN's 1951 Geneva Convention defines refugees as people who have left their own country because of a well-founded fear of persecution for reasons such as race, religion, nationality, political opinion, etc. The refugee system thus represents the policy domain (Laumann and Knoke, 
1987) that determines the status of refugee claimants and assists in the settlement of those individuals granted asylum. It encompasses the formation and implementation of policies and practices related to the rights of individuals to claim asylum; the procedures whereby claimants are awarded asylum; and the support provided to claimants and refugees. It is an interorganizational domain (Gray, 1989) or institutional field (Warren et al, 1974) that includes a number of government, nongovernment (NGO) and refugee organizations, in addition to individual refugees.

We employed a qualitative methodology (e.g., Gray 1989; Altheide 1988) in order to "understand the distribution of power, conflicts and concerns of interest, and the dynamics of their interaction” in these interorganizational domains (Brown 1980: 201). Eighty-six interviews were conducted (all in English, apart from two translations in Denmark), with public servants, politicians, NGO officials and refugees between 1990 and 1995. The interviews lasted between one and three hours and were tape-recorded. Every interviewee was guaranteed anonymity. We also examined documentary and archival evidence that included government statistics, annual reports, a variety of published documentation, reports of parliamentary speeches in the UK and Canada, as well as newspaper articles.

\section{Refugee Production: The “Official” Story}

Most refugees seeking asylum find shelter in refugee camps in neighbouring countries, often administered by the United Nations High Commission for Refugees (UNHCR). Some, however, flee further afield and arrive in Europe, North America or Australia. Upon entering a country, these individuals claim asylum and enter the country’s refugee system. This system will determine their status, decide whether they will be given refuge, and on what conditions. According to the official story, individuals are determined to 
be refugees as a result of a quasi-legal process, during which refugee claimants or their representatives present their case to officials who make a judgement of that claim.

In the UK, civil servants in the Asylum Division of the Home Office hear the cases of individuals who request asylum. Two categories of asylum exist: full refugee status and exceptional leave to remain, which confer different rights concerning settlement and citizenship although neither category confers the immediate right to permanent residence. The central NGO, in terms of providing advice and non-legal services to refugees is the British Refugee Council, a government-funded umbrella body; the Refugee Legal Centre, another government-funded NGO, provides the majority of refugees with legal representation. A number of small, but active, refugee organizations provide advice and support to individual refugees. Some of these organizations are members of the British Refugee Council, while others are members of the Refugee Forum, which contests the right of white-run NGOs to represent refugees.

Individuals claiming asylum in Canada undergo a hearing conducted by members of the Immigration and Refugee Board. Private lawyers and solicitors and members of NGOs often represent individual refugees. Once awarded asylum, refugees usually obtain landed immigrant (permanent residence) status and may apply for citizenship in and qualify for the same rights as other immigrants. The Canadian Council for Refugees represents over 100 NGOs across the country. Refugee organizations are less common than in the UK, but one organization we examined was the Ghanaian Refugee Union, which secured representation on the Council's executive committee and helped to create the Montreal Coalition of Refugees.

In Denmark, the Directorate for Aliens initially hears refugees’ claims for asylum. If the Directorate does not grant asylum, the case is referred to the Refugee Board, where a tribunal chaired by a judge, with representatives from the Danish Refugee Council (the main 
NGO), various ministries and the Bar Association, hears the claim and decides whether or not to grant asylum. Refugees awarded asylum in Denmark secure permanent residence and most of the same rights as Danish citizens. Unlike the other two countries, refugees undergo an 18month integration program during which time they receive government support. Refugee organizations are virtually non-existent in Denmark.

\section{Refugee Production: The “Unofficial” Story}

Our research challenges this official story — that refugees are produced as a result of a rational decision making process that examines the "facts" and seeks to determine the "true” status of those individuals claiming asylum. It argues that the official story glosses over much of the experience of becoming a subject called a refugee. Refugees exist in a "no man's land” where various organizational processes define their contested identity, whether as “refugee”, “immigrant”, “citizen”, “economic migrant” or “deportee”. To claim refugee status is to submit to processes that grant or deny membership of organizationally contrived categorizations. It is all too evident, then, that the identity of refugees is not "given" but is a “transparent” example (Eisenhardt 1989) of complex processes of social production. Thus the study of refugees is particularly helpful in our analysis of the social production of identity.

Our research draws attention to the existence of three broad stakeholder groups in refugee systems — government, NGOs and refugee organizations — with different and often conflicting interests. By examining these stakeholders and the interactions between them, we are better placed to understand the nature of refugee systems in general and the process of refugee production in particular. For example, bridging organizations, such as refugee councils, mediate the relationship between the core and periphery of these activist domains in different ways. These relationships shape and are shaped by the values, culture and strategies 
of the various organizations and have important implications for the different ways in which refugees are constituted (Lawrence and Hardy, 1999).

Our research has also demonstrated that power and politics are inseparable from the processes of social construction which create refugee systems. The ability to influence these systems depends on having access to formal authority, control over key resources, or the ability to discursively manage legitimacy. When a lack of resources and formal authority reduces the prospects of influence, discursive legitimacy provides a way for ostensibly less powerful organizations — such as refugee organizations — to ensure recognition and participation in the domain. While formal authority and resource dependency may provide some organizations with a measure of control within an existing institutional frame, discursive processes can enable organizations to modify or maintain the institutional frame within which traditional power is exercised. So, while the government ostensibly has considerable power through its formal authority and control of resources — primarily the enactment of legislation and the administration of the determination system — other organizations participate in the production of refugees through their discursive activities (Phillips and Hardy, 1997).

Our studies show specifically how the concept of a "refugee" is discursively constituted as individual organizations struggle to establish a particular understanding of a "refugee” conducive to their goals and interests. So, for example, individual organizations construct refugees as "genuine” or “economic" and "dependent” or "autonomous." Discursive activities by the government tend to construct refugees as economic migrants and bogus claimants, which justifies its role in limiting access and developing determination procedures to "weed out" abusers. NGOs and refugee organizations tend to challenge the construction of this refugee identity. Their organizational existence rests on providing the support and protection that genuine refugees deserve. 
Similarly, the stereotypical view of refugees as helpless, defenceless individuals, in desperate need of protection and care has a distinct advantage for the government in that it provides further justification of the determination process. While the creation of painstaking measures to keep people out of the country seems misplaced if those individuals are contributing members of society, controls are vindicated if needy refugees are likely become a “drain” on the country's resources. This identity also benefits NGOs, whose existence and funding — is justified by dispensing services to "clients” who are unable to look after themselves. However, it threatens refugee organizations, which promote the identity of an autonomous, competent, capable, self-reliant refugee and seek to undermine the existence of NGOs and their right to speak on behalf of refugees (Phillips and Hardy, 1997).

Thus a struggle emanates between various organizations in the refugee system, whose discursive activities are closely linked to their different interests.

Thus government is in the "business" of determination, which is enhanced by juxtaposing deserving refugees against "economic migrants"; the latter to be unmasked by the determination system. White-led NGOs that speak and advocate on behalf of refugees are in the "business" of service provision, which is enhanced by refugees as needy "clients" to whom professionals can dispense services. Refugee community organizations are in the "business" of self-help, which is enhanced by refugees as fully functioning and equal 'members' of society (Hardy and Phillips, 1997: 11)

These discursive struggles do not only occur at the organizational level: they are also influenced by broader discourses that exist at the societal level. For example, local activities are shaped by broader struggles between the discourses of human rights and sovereignty, and between paternalism and empowerment. In addition, broader discourses provide resources for actors. For example, strategies used by the government to promote the concept of sovereignty could draw on immigration discourses that portrayed refugees as frauds. Strategies used by NGOs to advance human rights and paternalism could draw on discursive depictions of the government as incompetent, corrupt and cruel, and portraits of the immigration system as too 
slow, too tough and inconsistent. Refugee strategies to advocate empowerment were hampered, however, in that immigration discourses provided no compatible images. Consequently, we might expect to see refugees attempt to draw on other discourses, such as community empowerment, race, and political correctness in order to find a subject position from which to influence the refugee system. Thus complex intertextual and interdiscursive relations surround and permeate refugee systems, shaping the activities that go on within them (Hardy and Phillips, 1999).

In summary, a “conventional” analysis shows how struggles between multiple, competing translations by actors, which take place at different levels, produce the refugee subject. At the broadest level, the idea of a refugee is defined through an ongoing discursive process involving a wide range of actors. At a more micro level, a subset of organizations engage in specific discursive activities, which are influenced by various broader discourses.

\section{A Reflexive Approach}

The previous analysis shows that there is no single refugee subject but, rather, multiple, fragmented refugee subjects that are socially and organizationally constituted through the shifting networks of the domain. While offering insights into the construction of identity, this analysis remains “conventional” in that we have assumed the traditional privilege of the researcher to tell the reader about refugees. We have focused only on the network of actors in the refugee system but, as our study was designed, executed, written up and published, another network was implicated — that of the research community of which we are a part. To understand the role of these particular actors, a more reflexive analysis is required.

We use actor-network theory to provide a more reflexive approach. It includes an examination of our activities — the researchers who carried out this study — as well as those 
of the research community who acted as reviewers, editors, readers, and who wrote the papers and books we drew on in framing our studies as legitimate management research. We explore the struggles between different actors engaged in translation strategies, in this case, our interviewees, ourselves as the researchers, and the research community. We focus on the four stages of translation, during which identities and relationships of the actors are defined. Problematization refers to the ways in which actors become indispensable by defining the “problem.” Interessement alludes to the processes by actors are locked into particular roles. Enrolment strategies obtain consent and address resistance. Mobilization secures members’ support for representatives of the various collectivities.

We explore how the resulting research subject is the product of this wide network of actors all acting strategically to control the production of "facts.” As a result, the research “products” — published papers — bear only a limited resemblance to our original intentions. Our interest in refugee rights and empowerment was translated into work on collaboration, the discursive construction of identity and, finally, reflexivity. While we have a degree of agency, the networks in which we are embedded help shape our translation. The need to appeal to the actors in the refugee domain and the broader research community — the need to pass through a range of obligatory passage points — results in our research being translated by other actors, including interviewees and the research community.

\section{Interviewees}

For us to represent our research subjects to the research community, we relied on actors in the refugee system to represent the refugee system to us. From an actor network perspective, the interviewees translated the researchers. The problem from the perspective of these interviewees was the promotion of their particular "story" about the refugee system. Thus the interview became an obligatory passage point through which we as researchers had 
to pass if we were to learn the interviewee's story of the system. Attempts were made to fix identities: we were sympathetic observers who were willing to work hard to "get it right"; interviewees were truthful participants helping us in our pursuit of verifiable knowledge.

[Micro-sociological research] sees such data as unspecified collaborative products created during the interview in accordance with the practical procedures and background assumptions of participating actors (Knorr-Cetina, 1981: 13).

In our interviews, other identities were also implicated. For example, when the interviewee was a government decision-maker, refugees were likely to be constructed as potential liars, while decision-makers were honourable public servants. If the interviewee was a refugee, refugees were represented as genuine victims, decision-makers were often ill informed, and NGOs often paternalistic. If the interviewee was a NGO representative, refugees were often constructed as clients to whom NGOs tried to dispense important services, usually hampered by inadequate government funding and racist attitudes among decision makers.

Our consent was obtained through enrolment strategies that showed how refugee issues were fundamentally related to legitimate concerns - for example, to sovereignty, as in the case of decision-makers, or to humanitarianism in the case of NGOs and refugees. Mobilization occurred as the interviewees helped to bolster our credibility with the research community by providing access to anecdotes, reports, statistical information and other interviewees that, in turn, further legitimized our research. In this way, the interviewee’s story about the refugee system was more likely to secure wider acceptance.

\section{Researchers}

Our translation strategies are directed at both the research subjects whom we interview and members of the research community reading this paper. Like all empirical researchers, we must deal simultaneously with two translation strategies. On the one hand, we must develop a translation strategy to deal with the network of actors that make up our 
research study, while on the other we must develop a strategy to deal effectively with the research community, members of which will (hopefully) publish and read our results. It is this need to manage two translation strategies that characterizes the role of the researcher, and it is out of the tension and compromise of these two strategies that empirical research arises.

In translating our research with reference to interviewees, our aim was to ensure that they participated in our interviews, answered our questions, and provided the information that we needed. In this regard, our task was not onerous — we required a couple of hours of their time and the answers to a few questions. If interviewees provided access to reports or to other actors, then so much the better. We thus problematized the issue in the following way: as researchers, we were representing their domain to other academics and, insofar as interviewees wanted to ensure that their story was represented, they had to participate in our interviews. Thus we became an indispensable part, for a brief while at least, of the process. We then stabilized identities, particularly our own — as legitimate, scientific researchers from reputable universities who were, at the same time, sympathetic to the views of our interviewees.

The identity of our interviewees was stabilized as passive research subjects with a story to tell, willing to talk honestly and insightfully, but not to intervene in our research. We wanted to frame them, not the other way round. We tried to enrol them by saying that the research was useful, that it was important to participate if they wanted their interests represented, and by implying that they were good citizens by participating in the scientific research, and bad ones if they did not. Finally, we mobilized through our selection of certain "key” actors who represented the "main” interest groups. The task was relatively easy as those who might disagree with the quotations and statements made by their "representatives" are unlikely to be reading Human Relations: they are immobilized by their absence. In this regard, our strategies match those of other researchers: 
Though I clearly empathized with, sought to empower and indeed suffered for my support of, the disadvantaged in the setting, my summative account was staged as a dramatized monologue. The voices of other indigenous participants in the setting, that I so carefully recorded, were indeed extensively presented "verbatim" in the text. However, the presence of these indigenous voices, though apparently dialogic was in actuality dramatic, in which their contribution had been selected and staged as typifications of a culture to be represented (Jeffcutt, 1994: 251).

To achieve our aims in relation to the research community, we must translate our research in a way that makes this paper — and others — an obligatory passage point through which readers must pass. This requires a strategic frame for the paper — refugees are not a typical or particularly compelling topic of study in the organization and management literature. In fact, two initial attempts to secure research funding for a study of refugees were rejected by the Canadian Social Sciences and Humanities Research Council. Funding was only finally secured when the project was presented as part of a larger program of study on “collaboration”. Hence many of our papers focus on collaboration in interorganizational domains (e.g., Hardy, 1994; Hardy and Phillips, 1998). In other words, to learn about collaboration, readers of these papers had to pass through this study of refugees.

The current paper attempts to make reflexivity its obligatory passage point. Using the existing literature, we focus on the importance of reflexivity in organization studies. Citing a range of published articles, including recent Human Relations articles on reflexivity (Linstead, 1994; Holland, 1999), we claim that our interest is "in approaches to reflexivity in OMT” and make a case for our contribution to this discussion. Then, by citing refugees as a “transparent” example (Eisenhardt, 1989), as we did in our methodology, we ensure that they become an integral part of this paper. In doing so, we establish a new identity for refugees, who are now subjects produced by particular organizational processes. As researchers of refugee systems, we establish our own, indispensable identities — only we can show how an organizational system produces refugee subjects. Thus we become the lynchpin of an alliance 
that binds together those who represent the organizational studies research community and those who populate refugee systems: before our intervention, these networks existed but were not usually connected to each other.

Interessement requires that alternative identities that might challenge our problematization be barred from the discussion. So interviewees who might resist this categorization speak only through our fabrication; others are silenced — simply not interviewed, not quoted, and not cited. More difficult is the need to ensure that only the "right” reviewers and readers read our work. In doing this, it is important to locate ourselves in specific conversations about reflexivity (those in OMT), while distancing ourselves from other conversations about reflexivity (e.g., in the sociology of knowledge) to ensure the appropriate reviewers and readers.

No matter how numerous and how well stacked are its resources, an article has not got a chance if it is read just by any passing reader. Naturally, most of the readership has been defined by the medium, the title, the references, the figures and technical details. Still, even with the remainder it is still at the mercy of malevolent readers. In order to defend itself the text has to explain how and by whom it should be read. It comes, so to speak, with its own user's notive, or legend (Latour, 1987: 52).

For example, compared to the treatment of reflexivity in science and technology studies, our approach is "rather naïve”, as one reviewer pointed out. Thus, we must make clear that our focus is on OMT.

Similarly, we must ensure that researchers more familiar with refugee systems, immigration policies and international law are not in a position to resist our story. Thus we submit this paper to Human Relations and not to Refugee, The Journal of Refugee Studies or International Migration Review. ${ }^{2}$ We position ourselves so that we alone speak for our

\footnotetext{
${ }^{2}$ Research conducted under the rubric of "refugee studies" as opposed to organization studies, has examined determination procedures often from a legal perspective (e.g., Gammeltoft-Hansen 1985; Goodwin-Gill 1978; 1983; Grahl-Madsen 1972, 1983; Leibowitz 1983 ; MacDonald 1989; Martin 1988; Scanlan and Loescher 1983; Zolberg 1988; Zucker 1983a,1983b; Zucker and Zucker 1987) or from a technical perspective i.e. detailing
} 
research subjects, whom we represent in such a way that the research system listens to us and publishes our paper. Thus, we give voice to certain stories, and try to make our story stick.

Our enrolment strategies secure the consent and participation of certain interviewees from the refugee system through quotations. We also seek to enrol our readers through traditional means, for example methodological rhetoric and the citation of previous literature (see Watson 1995); by appealing to the interests of Human Relations readers and by using an "unusual” case — that of refugees. By demonstrating our expertise in non-traditional research, as well as showing more conventional research credentials, we hope to enrol our readers in our project.

Finally, we mobilize the research community. We prepare to undercut any claims that our work is illegitimate, unworthy and unscientific by promoting the case for reflexivity, thus trying to expand the definition of what is constituted as legitimate, worthy, scientific research. Thus, we argue that if organizational researchers are to understand their role, they must speak a new language — that of reflexivity. By suggesting a meta-theoretical framing for this language, we hope to be allowed to speak.

In employing these strategies, we do what every researcher does: operate within a research system that defines "good" research, what it looks like and how to recognize it (e.g.,

procedures (e.g., British Refugee Council 1987a, 1987b, 1988; Danish Refugee Council 1988; 1989a; 1989b; ECRE, 1983; Immigration and Refugee Board 1988; 1989a; 1989b; Young 1989). Another body of work critiques government policies (e.g., Adelman 1991; Allen and Michnick 1987; Benard 1986; Joly 1990; Joly and Cohen 1989; Malarek 1987; Matas 1989; Whitaker 1987; Cohen 1994); some of which is specifically political (e.g., Amnesty International 1987; 1991; British Refugee Council 1987a; Refugee Council 1991). A stream of work, often adopting a social work perspective, tackles particular “problems” (e.g., McInnis 1986); examines refugee demographics (e.g., Huyck 1983) and psychological effects of being a refugee (e.g., Lee 1989; Stein 1986; Wali 1989). Another body of work compares national policy (e.g., Harrell-Bond 1989; Hawkins 1989) and other international dimensions (e.g., Loescher and Monahan 1989). Finally, research is also concerned with refugee resettlement (e.g., Kormendi 1987; Lanphier 1983, 1989; Neuwirth, 1988; 1989; Steen 1993; Stein 1983; Zucker 1983b). 
Watson, 1995). Consequently, our translation is not unfettered: the research system also translates, employing its own technologies of control to which we submit (literally and metaphorically. We are unable to escape the obligatory passage point of the submission process even though we resist it in the way we problematize, interest, enrol and mobilize. We represent our research subjects in ways that strengthen our translation but, if the readers and reviewers are not convinced, our translation is incomplete. Another constraint that we have to manage is the interaction of two translation strategies - involving the research community and our research subjects.

\section{The Research Community}

The research community is made up of the network of researchers, editors, reviewers, journals and publishers who together produce knowledge concerning organizations and management. We are concerned with this broader community, but we also explore some of the activities of Human Relations, as a particular example within it, in more detail below. In the interests of brevity, we will simplify our analysis to focus on a selection of key actors.

Many of the practices in this field are highly institutionalized and common to all academic journals; other practices differentiate journals from each other and thus provide a source of variation. As far as the research community is generally concerned, the problem is one of the advancement of knowledge and the publication of research that furthers that objective. So, for example, Administrative Science Quarterly asks of submissions: “does this work (1) advance understanding, (2) address administration, (3) have mutual relevance for empirical investigation and theoretical analysis?” (notice to contributors). The Academy of Management Journal's information for contributors states that a "significant 'value-added' advance to the field's understanding of an issue or topic is critical to acceptance for publication.” Human Relations' guidelines argue that papers must “advance knowledge in the 
sense that both the subject and method of investigation address an arena of wider interest ... outside a particular specialism.” Thus the review process becomes an obligatory passage point to which researchers must submit in order that their contribution to the advancement of knowledge can be ascertained.

Implicated in this problem are a number of important identities. First, researchers are the people who submit manuscripts. They are capable of doing good research with the help of editors and reviewers; however, they do not always do good research and, therefore, a review process is needed to screen out bad research, help improve research with potential, and accept good research. The fact that some researchers submit "shoddy" work legitimates the need for accepted research protocols; the fact expert reviewers are willing to provide community service through their review activities enacts and reproduces those protocols. Second, journal identities are created with a contested hierarchy of prestige, together with the particular focus of the journal. The journals' identities are stabilized, despite changes in editorship that, in some journals can be every few years, through such mechanisms as the publication of studies of citations (e.g., Tahai and Meyer, 1999) and acceptance rates (the lower the better). There is also a self-fulfilling prophecy, as the "best" journals tend to attract the "best" submissions, reviewers and editors, thereby maintaining their position.

The enrolment of authors is obtained through seduction — the publication of "good" papers, while "bad” ones are consigned to obscurity or, at least, another journal. Researchers, who carry out research "responsibly”, who play by the accepted rules, are allowed to speak for and to the research community with little danger of resistance. And, in fact, if resistance does find a voice, it is often channelled back through the original obligatory passage point — a rebuttal or series of exchanges in one of the major journals. The various journals mobilize a vast number of academics through the submission, review and editorial process. Once involved with a journal in one of these capacities, it becomes difficult to resist translation. 
Human Relations enacts many of these highly institutionalized practices. For example, its peer review process is an integral part of getting paper published in this journal; it has special issues, an editorial board, and reviews like any other journal; it holds a reception at the Academy of Management meetings. However, from the perspective of Human Relations, it is important that it, rather than other journals, becomes the obligatory passage point for as many authors (and readers) as possible. Consequently, it engages in practices that differentiate it from other journals in ways that will attract authors and readers. It does so by problematizing the need for interdisciplinary and relevant research on organizations in order to advance knowledge.

The Tavistock Institute founded Human Relations in the belief that social scientists should work toward integrating their disciplines in the attempt to understand the complexities of human problems, and that both researchers and practitioners should translate understanding into action by making links between theory and practice. Such linkages increase the likelihood of relevance and of innovative research in emerging fields of work, taking the social scientist outside traditional areas and approaches. We emphasize our openness to such thinking (Human Relations editorial guidelines).

The identity of the journal is stabilized in a number of ways. For example, the journal actively solicits manuscripts from contributors who are "working within their own discipline in a way which is yet transcendent of it or which deliberately crosses disciplinary boundaries” (from introduction to editorial guidelines). Competing identities are banished. For example, Human Relations distinguished from many other journals in that it discourages both traditional methodologies and the strong emphasis on method that characterize many journals. Thus the researchers who submit to Human Relations are not "traditional" researchers relying on questionnaires: "papers which report the findings of studies which use cross-sectional designs and self-report questionnaire measures are discouraged” (guideline \#8). Similarly, the journal's identity as “different” is also stabilized:

While a description of the theoretical frame adopted by an author necessarily includes some consideration of methodology, such consideration does not 
normally provide more than a small proportion of the paper's content. An overly long explanation of why particular norms and standards have been chosen detracts from discussion of substance (guideline \#4).

Identities are further locked into place as authors are "requested to indicate to the editors how the paper meets their requirement in a covering letter” regarding advancement of knowledge (guideline \#2), methodology (guideline \#8), following all the guidelines (Submission of Manuscripts, point \#1) and originality (Submission of Manuscripts, point \#2).

Human Relations enrols in much the same way as other journals — authors are encouraged to participate in exchange for the publication of their work. In this case, an additional attraction — for some writers at least — is the ability to publish non-traditional organizational research in a respected journal. For writers frustrated with the more standardized and restrictive publication norms associated with some management journals, Human Relations offers an opportunity for "alternative” work in OMT. By enroling contributors and reviewers in this way, the journal also mobilizes the communities they represent. As academics publish in and review for Human Relations, they enhance its academic credibility, making it a more desirable outlet for the academic community.

In summary, the refugee as a research subject is not the simple product of the determination system, nor even of the interaction of decision-makers, refugees or any other actor who populates the "reality" he or she experiences. This refugee is produced through the translation strategies of the researchers who study him and, because our research is shaped by the translation strategies of the wider research community, through us, these actors also contribute to the production process. This refugee is not the refugee to be found in Refugee or the Journal of Refugee Studies, where different research protocols, traditions and representations apply. This refugee is produced by us, by the way we represent her; the background orchestration of organization and management theory; and the participation of the interviewees. This refugee is one representation among many in which a host of 
characters, not least OMT itself, is implicated. Nor are refugees the only subjects being produced; all the actors are — decision-makers, NGO representatives, researchers and research community.

\section{Conclusions: Representation and the "Subject" of Organization Studies}

Our research identifies the fragmented, ambiguous, contested subjects translated by actors in the refugee system; and related, but different subjects translated by the researchers carrying out the study and the protocols associated with organization studies. The first subject is a social product of the discursive activities and strategies of those who make up the network of interested actors surrounding the subject. This subject, and the network that produces it, exist independently of our (the researchers') observations of them. As researchers, we produce research subjects within a different network of actors and by applying theoretical, methodological, and representational frameworks to render particular social subjects visible.

Thinking about research reflexively in this way raises important questions about the role of the researcher in constructing (or reconstructing) the subject of his or her research. The idea of reflexivity reinforced the fact that there is an important distinction to be drawn between the social subject produced in its social setting and the research subject produced by the researcher and his or her research community. While we may succeed in making the social subject visible to the research community, we do so only by producing the research subject.

Researchers never leave their own microsituations; what they do is compile summaries by a series of coding and translating procedures until a text is produced which is taken as representing a macroreality, standing above all the microsituations that produced it (Collins 1981: 988).

We draw on the ambiguous and contested social subject in order to re-represent it. The social subject may exist almost independently of the research system if the researchers and research 
community are peripheral to the network that surrounds it (as in this case), but the researcher and research community are inevitably implicated in the production of the research subject. This leads us to consider four important issues related to reflexivity.

First, the framework we have presented here reaffirms the critical importance of recognizing that the social construction of science is a process carried out through a network. While the researcher plays a critical role in producing research, the conventions, rules, and practices common to his or her research community are also critically important. As others have demonstrated, there is no way for an individual to produce "science" — only a community can create such legitimated knowledge. Thus the research community is inevitably implicated in the production of knowledge and of the research subject. Research methods that produce "objective" knowledge are really nodal points through which researchers must pass in order to produce particular — acceptable — constructions of the research subject. Equally, other research approaches also use particular practices and conventions to convert social subjects into legitimate research subjects.

[T] he impersonal conventions of the research paper not only conceal but actively misrepresent the complex and diverse processes involved in the production and legitimation of scientific findings (Mulkay, 1992: 69).

It is, then, these kinds of practices (peer review, style guides, and other standardized practices), as well as our own individual activities, that we need examine to be truly reflexive.

Second, recognizing the constructed nature of the subject and the role of networks in the research process helps avoid two types of romanticism. First, there is no "real" subject. The social subject is as equally contrived and constructed as the research subject. Arguments about getting close to the social subject are simply alternative ways of constructing a research subject. Second, romantic ideas about the researcher's ability to heroically avoid bias and produce objective knowledge are equally misguided. There is no objective or true knowledge, 
simply more or less legitimated knowledge. The production of knowledge necessarily involves a network and is possible only when sufficiently developed practices exist to legitimate particular representations.

Third, the existence of these two contested and ambiguous subjects provides us with a theoretical frame with which to be more reflexive about the role of the researcher, the research community, and the relation of the research community to the settings from which the research subject is drawn. The difference between the social subject and the research subject is a way to understand the effects of the research, which is of particular concern when researchers intervene in the domains they study, as is often the case in organization and management research. From our perspective, research can have two kinds of effects. On one hand, research can change the nature of the research subject by changing the understandings, practices, and the like that characterize the research field (see Mulkay, 1992: 110-118). The construction of a research subject is, as this study shows, always a political act - the outcome of the translation struggle as shaped by the relative power of the participants.

[R]epresentations as understood here are not imaginary pictures of the world which belong to the realm of free-floating ideas. Summary representations are not only routinely and actively constructed in everyday life, they are also routinely invested with faith and interests, they are fought over and manipulated. As the study of science has shown, to construe a certain representation of the world is in principle always at the same time a matter of truth (correspondence, equivalence) and a matter of political strategy, that is of imposing one's say and of instituting certain consequences with or against others (Knorr-Cetina 1981: 36-37).

Alternatively, research can affect the network that surrounds the social subject by transplanting the results of a study back into the network, which is equally political. In this case, if the researcher and research community engage more influentially in the network of actors that surround the social subject (as the calls for more influential research by Hambrick [1994] and Pfeffer [1993] advocate), then potential exists to change both the research subject and the social subject. Given that different constructions of the social subject may evoke 
quite different practices and experiences for those individuals (Phillips and Hardy, 1997), such moves clearly raise a range of ethical questions regarding the effect that researchers have on the social subject. Reflexivity does not provide a solution to this problem but it does remind us of the importance of these dynamics and raise the issue for further discussion.

Finally, the difference between the social subject and the research subject grows out of the discursive practices between two communities or networks, not out of the activities or biases of a single researcher. The researcher can only produce research subjects by engaging with a community of researchers. To understand how the research subject is produced requires reflexive research that involves an examination, not just of the researcher although that is critically important, but also the community of which the researcher is a part. Reflexivity certainly involves self-critique and being able to account for our own theorizing but, equally, it involves recognizing that we operate in complex networks that hold in place certain approaches to representation. Thus we build on Holland's (1999) levels of reflexivity in research (also see Chia, 1996). Our “conventional” analysis conformed to his first level; our "reflexive” analysis, like Holland's highest level, acknowledges the social construction of research and theory, but also explicitly includes consideration of practices and protocols in the research community.

In this way, we are able to reflexively examine the relationship of the researcher to the research process and the "knowledge” it produces. Building on this observation, we believe that the definition of reflexivity must be broadened. Instead of the singular focus on the researcher, we need a definition that includes the research community in which the researcher and the research subject are embedded. We, therefore, define reflexivity as an awareness of the situatedness of scientific knowledge and an understanding of the researcher and research community from which the knowledge has appeared. Whereas objective knowledge claims to 
be un-situated — true any time and any place — reflexive knowledge is situated and includes a recognition of the multiple translation strategies that bring it into being.

When understood this way, reflexivity represents a challenge for researchers: how to develop new practices of representation that will allow this kind of knowledge to be produced and disseminated. The translation strategies of the research community are currently insufficient to allow this kind of reflexive knowledge to be produced. Therefore, the conversation that is taking place regarding reflexivity must begin to focus on representation as a limitation on reflexivity in our field:

All forms of representation are limited portrayals. Some modes provide more insights and understandings of organizational processes than do others. A major difficulty in producing text is the politics of representation. Organizational researchers need ways to open up text for multiple readings; to decenter authors as authority figures; and to involve participants, readers and audiences in the production of research. One venue for achieving these goals is to seek alternative ways of presenting research reports - ones that challenge conventional modalities, ground research in historical processes, promote reflexivity, and open up our text to an infinitude of meanings (Putnam, 1996: 386).

Simply recognizing the situatedness of knowledge is therefore not enough. Instead, we need to develop new representational practices that allow researchers, at least some of the time and in some cases, to reflect upon the system out of which their research arises. 


\section{Bibliography}

ADELMAN, H. Refugee determination: Commentary. Refugee, 1991, 11(2), 8-18.

ALLEN, H.S. AND MICHNICK, K. Refugee measures imperil Canada's humanitarian image. Perception, 1987, 10(5), 32-34.

ALTHEIDE, D. L. Mediating cutbacks in human services: A case study in the negotiated order. Sociological Quarterly, 1988, 29(3), 339-35.

ALVESSON, M. and SKOLDBERG, M. Reflexive Methodology. London: Sage, 1999.

AMNESTY INTERNATIONAL. Deficient policy and practice of asylum seekers. London: Amnesty International (British Section), 1991.

AMNESTY INTERNATIONAL. Exiled: Asylum seekers in the UK. London: Amnesty International (British Section), 1987.

ASHMORE, M. The reflexive thesis, Chicago: University of Chicago, 1989.

ASTLEY, W.G. Administrative science as socially constructed truth. Administrative Science Quarterly, 1984, 32: 499-512.

BECKER, H. Sociological work: Method and substance. Chicago: Aldine, 1970.

BENARD, C. Politics and the refugee experience. Political Science Quarterly, 1986, 101(4), 617-636.

BOURDIEU, P. and WACQUANT, L.J.D. An invitation to reflexive sociology. Cambridge: Polity, 1992.

BRITISH REFUGEE COUNCIL. Refugee advisor's handbook. London: British Refugee Council, 1987a.

BRITISH REFUGEE COUNCIL. Settling for a future: Proposals for a British policy on refugees. London: British Refugee Council, 1987b.

BRITISH REFUGEE COUNCIL. Working together: Refugees and local authorities in London. London: British Refugee Council, 1988.

BROWN, L.D. Planned change in underorganized systems. Systems theory for organization development. T. G. Cummings, ed., New York: Wiley, 1980.

CALAS, M.B. and SMIRCICH, L. Voicing seduction to silence leadership. Organization Studies; 1991, 12(4), 567-602.

CALLON, M. and LATOUR, B. Unscrewing the big leviathan: How actors macro-structure reality and how sociologists help them to do so. Advances in social theory and methodology. K. Knorr-Cetina and A.V. Cicourel, eds., Boston: Routledge and Kegan Paul, 1981. 
CALLON, M. Some elements of a sociology of translation: Domestication of the scallops and the fisherman of St. Briene Bay. Power, action and belief: A sociology of knowledge. J. Law, ed., London: Routledge, 1986.

CAMPBELL, D. and STANLEY, J. Experimental and quasi-experimental designs for research on teaching. Handbook for research on teaching. N. Gage, ed., Chicago: Rand McNally, 1963.

CHIA, R. Organizational analysis as deconstructive practice. Berlin: Walter de Gruyter, 1996.

CLEGG, S. and HARDY, C. Representations. Handbook of organization studies, S.R. Clegg, C. Hardy, and W.R. Nord, eds., London: Sage, 1996.

CLIFFORD, J. and MARCUS, G., eds, Writing culture: The poetics and politics of enthography. Berkeley: University of California, 1986.

COHEN, R. Frontiers of identity: The British and the others. London: Longman, 1994.

COLLINS, R. On the microfoundations of macrosociology. American Journal of Sociology. 1981, 86(5), 984-1013.

DANISH REFUGEE COUNCIL. Current asylum policy and humanitarian principles. Copenhagen: Danish Refugee Council, 1988.

DANISH REFUGEE COUNCIL. Programme of integration. Copenhagen: Danish Refugee Council, 1989a.

DANISH REFUGEE COUNCIL. A guide to the Danish Refugee Council. Copenhagen: Danish Refugee Council, 1989b.

DENZIN, N.K AND LINCOLN, Y.S. Entering the field of qualitative research. Handbook of qualitative research, (eds.) N.K. Denzin and Y.S. Lincoln, London: Sage, 1994, 1-19.

EASTERBY-SMITH, M. and MALINA, D. Cross-cultural collaborative research: Toward reflexivity, Academy of Management Journal, 42(1), 76-86, 1999.

ECRE (EUROPEAN CONSULTATION ON REFUGEES AND EXILES). Asylum in Europe: A handbook for agencies assisting refugees. London ECRE (3rd ed.), 1983.

EISENHARDT, K.M., Building theories from case study research. Academy of Management Review, 1989, 14(3), 532-550.

GAMMELTOFT-HANSEN, H. The status of refugees in Denmark. International Institute of Humanitarian Law. (1), 5-137, 1985.

GERGEN, K. The saturated self : dilemmas of identity in contemporary life. New York: Basic Books, 1991.

GLASER, B. G. and STRAUSS, A. L. The discovery of grounded theory: Strategies for qualitative research. Chicago: Aldine, 1967. 
GOODWIN-GILL, G.S. International law and the movement of persons between states. Oxford: Clarendon Press, 1978.

GOODWIN-GILL, G.S. The refugee in international law. Oxford: Clarendon Press, 1983.

GOULDNER, A.W. The coming crisis of Western sociology, London : Heinemann, 1970.

GRAHL-MASDEN, A. The status of refugees in international law: Volume II. Leiden: Sijthoff, 1972.

GRAHL-MASDEN, A. Identifying the world's refugees. Annals of the American Academy of Political and Social Science, 1983, 467, 11-23.

GRAY, B. Collaborating. San Francisco: Jossey-Bass, 1989.

HAMBRICK, D. C. What if the Academy actually mattered? Academy of Management Review, 19(1): 11-16, 1994.

HARDY, C. Underorganized interorganizational domains: The case of refugee systems. Journal of Applied Behavioral Sciences, 1994, 30(3), 278-296.

HARDY, C. and CLEGG, S. Relativity without relativism: reflexivity in post-paradigm organization studies. British Journal of Management, 1997, 8, S5-S17.

HARDY, C. and PHILLIPS, N. Strategies of engagement: Lessons from the critical examination of collaboration and conflict in an interorganizational domain. Organization Science, 9(2), 217-230, 1998.

HARDY, C. and PHILLIPS, N. No joking matter: Discursive struggle in the Canadian refugee system. Organization Studies, 20(1), 1-24, 1999.

HARRELL-BOND, B. Report of the Proceedings of the International Symposium on the Refugee Crisis: British and Canadian Responses, B. Harrell-Bond (ed.), Oxford: Refugee Studies Programme, 1989.

HATCH, M.J. The role of the researcher: An analysis of narrative position in organization theory. Journal of Management Inquiry, 5(4), 359-374, 1996.

HAWKINS, F. Critical years in immigration: Canada and Australia compared. Kingston, ON: McGill-Queen's University Press, 1989.

HOLLAND, R. Reflexivity. Human Relations, 52(4), 463-485, 1999.

HUYCK, E.E. The demography of refugees. The Annals of the American Academy of Political and Social Science, 1983, 467, 39-61.

IMMIGRATION AND REFUGEE BOARD. Refugee determination: What it is and how it works. Ottawa: Immigration and Refugee Board, 1988.

IMMIGRATION AND REFUGEE BOARD. Annual report. Ottawa: Immigration and Refugee Board, 1989a. 
IMMIGRATION AND REFUGEE BOARD. Backlog process: How the system works. Ottawa: Immigration and Refugee Board, 1989b.

JEFFCUTT, P. From interpretation to representation in organizational analysis: Postmodernism, ethnography and organizational symbolism. Organization Studies, 15(2), 241-274, 1994.

JERMIER, J.M. When the sleeper wakes: A short story extending themes in radical organization theory. Journal of Management. 11, 67-80, 1985.

JOLY, D. Refugees in Europe. Nottingham, UK: Russell Press, 1990.

JOLY, D. AND COHEN, P. Reluctant hosts: Europe and its refugees. Aldershot, UK: Avebury, 1989.

KAGHAN, W.N. and PHILLIPS, N. Building the Tower of Babel: Communities of practice and paradigmatic pluralism in organization studies, Organization, 5(2), 191-217, 1998.

KILDUFF, M. Deconstructing Organizations, Academy of Management Review, 18(1), 1331, 1993.

KNIGHTS, D. and MORGAN, G. Strategic discourse and subjectivity: Towards a critical analysis of corporate strategy in organisations, Organisation Studies, 12, 3, 251-273, 1991.

KNORR-CETINA, K. The micro-sociological challenge of macro-sociology: Towards a reconstruction of social theory and methodology. Advances in social theory and methodology. K. Knorr-Cetina and A.V. Cicourel, eds., Boston: Routledge and Kegan Paul, 1981.

KORMENDI, E. Refugees in Denmark. Copenhagen, Denmark: The Danish National Institute of Social Research, 24, 1987.

LANPHIER, C.M. Refugee resettlement: Models in action. International Migration Review, 1983, 17(1), 4-33.

LANPHIER, M. Host programmes and government/public participation. Report of the Proceedings of the International Symposium on the Refugee Crisis: British and Canadian Responses. B. Harrell-Bond, (ed.), Oxford, UK: Refugee Studies Programme, 1989.

LATOUR, B. Science in action: How to follow scientists and engineers through society. Cambridge MA.: Harvard University Press, 1987.

LATOUR, B. AND WOOLGAR, S. Laboratory life: The construction of scientific facts. Princeton, New Jersey: Princeton, 1986.

LAUMANN, E.O. AND KNOKE, D. The organizational state. Madison: University of Wisconsin Press, 1987. 
LAW, J. Organizing modernity, Oxford: Blackwell, 1994.

LAW, J. (ed.) A sociology of monsters: Essays on power, technology and domination. London: Routledge, 1991.

LAW, L. AND HASSARD, J. Actor network theory and after. Oxford: Blackwell, 1999.

LAWRENCE, T. AND HARDY, C. Building bridges for refugees: Toward a typology of bridging organizations. Journal of Applied Behavioral Science, 35(1), 48-70, 1999.

LEE, C. The mental health of refugees. Report of the proceedings of the international symposium on the refugee crisis: British and Canadian responses. B. Harrell-Bond, (ed.), Oxford, UK: Refugee Studies Programme, 1989.

LEE, N. AND BROWN, S. Otherness and the actor network. American Behavioral Scientist, 37(6), 772-790, 1994.

LEIBOWITZ, A.H. The Refugee Act of 1980: Problems and congressional concerns. The Annals of the American Academy of Political and Social Science, 1983, 467, 163-171.

LINSTEAD, S. Objectivity, reflexivity, and fiction: Humanity, inhumanity, and the science of the social. Human Relations, 47(11), 1321-1345, 1992.

LOESCHER, G. AND MONAHAN, L. Refugees and international relations. Oxford: Oxford University Press, 1989.

MACDONALD, I. Current law and practice in the UK. Report of the proceedings of the international symposium on the refugee crisis: British and Canadian responses. B. Harrell-Bond, (ed.), Oxford, UK: Refugee Studies Programme, 1989.

MALAREK, V. Heaven's gate: Canada's immigration fiasco. Toronto, Canada: Macmillan, 1987.

MARCUS, G.E. What comes just after 'post'? The case of ethnography. Handbook of Qualitative Research. N.K. Denzin and Y.S. Lincoln, (eds.), London: Sage, 1994.

MARTIN, D.A. The new asylum seekers: Refugee law in the 1980s. Dordrecht: Martinus Nijhoff, 1988.

MATAS, D. Closing the doors: The failure of refugee protection. Toronto: Summerhill, 1989.

MAUWS, M. and PHILLIPS, N. W. Understanding language games. Organization Science, 6(3), 322-334, 1995.

McHUGH, P., RAFFEL, S., FOSS, D. C., and BLUM, A. F. On the beginning of social inquiry. London: Routledge and Kegan Paul.

MCINNIS, K.M. Working with political refugees: New challenges to international social work. International Social Work, 1986, 29(3), 215-226. 
MULKAY, M. Science and the sociology of knowledge. Aldershot, England: Gregg Revivals, 1992.

NEUWIRTH, G. Refugee resettlement. Current Sociology, 1988, 36, 27-41.

NEUWIRTH, G. The settlement of Ethiopian refugees in Toronto. Ottawa: Minister of Supply and Services, 1989.

NEWTON, T. Agency and discourse: Recruiting consultants in a life insurance company. Sociology, 30(4), 717-739, 1996.

NOWOTNY, H. Actor-networks vs. science as a self-organizing system: A comparative view of two constructivist approaches. W. Krohn et al. (eds.), Selforganization: Portrait of a scientific revolution, Netherlands: Kluwer, 223-239.

O'CONNOR, E. Paradoxes of participation: A literary analysis of case studies on employee involvement. Organization Studies, 16(5), 769-905, 1995.

PARKER, M. Post-modern organisations or postmodern organisation theory? Organization Studies. 13(1), 1-13, 1992.

PFEFFER, J. Barriers to the advance of organizational science: Paradigm development as a dependent variable. Academy of Management Review, 18(4), 599-620, 1993.

PHILLIPS, N. Telling organizational tales: On the role of narrative fiction in organizational analysis. Organization Studies, 16(4), 625-649, 1995.

PHILLIPS, N. and HARDY, C. Managing multiple identities: Discourse, legitimacy and resources in the UK refugee system, Organization, 1997, 4(2), 159-185.

PUTNAM, L. Situating the author and text, Journal of Management Inquiry, 5(4), 382-386, 1996.

REFUGEE COUNCIL. At risk: Refugees and the Convention: Forty years on. London: Refugee Council, 1991.

RICHARDSON, L. (1994) Writing: A method of inquiry. Handbook of qualitative research, N.K. Denzin, and Y.S. Lincoln, eds., London: Sage, 1994.

RORTY, R. Contingency, irony, solidarity. Cambridge: Cambridge University Press, 1989.

SANDERLANDS, L. and DRAZIN, R. On the language of organization theory, Organization Studies, 10, 457-478, 1989

SCANLAN, J., AND LOESCHER, G. U.S. foreign policy, 1959-80: Impact on refugee flow from Cuba. The Annals of the American Academy of Political and Social Science, 1983, 116-137, 467.

SMIRCICH, L. and CALÁS. M. Organizational culture: A critical assessment. Handbook of organizational communication. F. Jablin, L.Putnam, K. Roberts and L. Porter, eds., Beverly Hills: Sage, 1987, 228-263. 
STAR, SUSAN LEIGH Power, technology and the phenomenology of convictions: On being allergic to onions. A sociology of monsters: Essays on power, technology and domination, S. Woolgar, ed., London: Routledge, 1991, 26-56.

STEEN, A. Varieties of the Tamil refugee experience in Denmark and England. Copenhagen: University of Copenhagen/Danish Centre for Human Rights, 1993.

STEIN, B.N. The commitment to refugee resettlement. The Annals of the American Academy of Political and Social Science, 1983, 467, 187-201.

STEIN, B.N. The experience of being a refugee: Insights from the research literature. Refugee mental health in resettlement countries. C.L. Williams and J. Westermeyer, eds., Minnesota, USA: Hemisphere, 1986.

TAHAI, A. and MEYER, M. J. A revealed preference study of management journals' direct influences. Strategic Management Journal, 20, 276-296, 1999

WALI, A. The psychiatric effects of traumatic stress on Afghan refugees. Report of the proceedings of the international symposium on the Refugee crisis: British and Canadian responses. B. Harrel-Bond, (ed), Oxford, UK: Refugee Studies Programme, 1989.

WILLMOTT, H. Breaking the paradigm mentality. Organization Studies, 14(5), 681-719, 1993.

WARREN, R., S. ROSE, and A. BERGUNDER The Structure of urban reform, Lexington, MA: DC Heath, 1974.

WATSON, T.J. Rhetoric, discourse and argument in organizational sense making: A reflexive tale. Organization Studies, 16(5): 805-821, 1995.

WHITAKER, R. Double standards: The secret history of Canadian immigration. Toronto: Laster and Orpen Dennys, 1987.

WOOLGAR, S., ed., Knowledge and reflexivity: New frontiers in the sociology of knowledge. London: Sage, 1988.

YOUNG, M. Canada's refugee determination system. Ottawa: Library of Parliament, Law and Government Division, 1989 (revised 1990).

ZOLBERG, A.R. The roots of American refugee policy. Social Research, 1988, 55, 649-678.

ZUCKER, N.F. The Haitians versus the United States: The courts as last resort. The Annals of the American Academy of Political and Social Science, 1983a, 467, 151-162.

ZUCKER, N.L. Refugee resettlement in the United States: Policy and problems. The Annals of the American Academy of Political and Social Science, 1983b, 467, 172-186.

ZUCKER, N.L. AND ZUCKER, N.F. The guarded gate: The reality of American refugee policy. San Diego: Harcourt, Brace, Jovanovich, 1987. 


\section{University Library}

\section{- M M I N E R VA A gateway to Melbourne's research publications}

Minerva Access is the Institutional Repository of The University of Melbourne

Author/s:

Hardy, C;Phillips, N;Clegg, S

Title:

Reflexivity in organization and management theory: A study of the production of the research 'subject'

Date:

2001-05-01

Citation:

Hardy, C., Phillips, N. \& Clegg, S. (2001). Reflexivity in organization and management theory: A study of the production of the research 'subject'. HUMAN RELATIONS, 54 (5), pp.531-560. https://doi.org/10.1177/0018726701545001.

Persistent Link:

http://hdl.handle.net/11343/116080 